\title{
SISTEM PENDUKUNG KEPUTUSAN UNTUK MENGEVALUASI KINERJA DOSEN PRODI DI STIKOM UYELINDO KUPANG MENGGUNAKAN METODE TOPSIS
}

\author{
Franki Yusuf Bisilisin ${ }^{1}$, Remerta N. Naatonis ${ }^{2}$ \\ Program Studi Teknik Informatika S1 STIKOM Uyelindo \\ Jl. Perintis Kemerdekaan No. 1- Kayu Putih, Kupang-NTT \\ E-mail: aenk.funk@gmail.com,reyheka@gmail.com
}

\begin{abstract}
STIKOM Uyelindo Kupang was established in the year 2000 as an information technology-based tertiary institution which has three study programs, namely under graduate of informatics engineering, diploma three informatics engineering and under graduate of information systems. The three study programs always strive to improve the status of accreditation by continuously improving internal quality and making accreditation a strategy to compete with other universities. To maintain quality, STIKOM Uyelindo Kupang, especially the undergraduate informatics engineering study program routinely monitors and evaluates the performance of lecturers. The problem that is often faced in routine monitoring and evaluation of lecturer performance is the performance evaluation process that is still objective so that to overcome these problems, a decision support system is needed that can assist in evaluating the performance of lecturers at STIKOM Uyelindo Kupang. The purpose of this study is to make a decision support system for the assessment of performance of lecturers of the first-degree informatics engineering study program at STIKOM Uyelindo Kupang using TOPSIS method. The results of this study are in the form of a desktop-based application that can facilitate the monitoring and performance evaluation teams of lecturers in evaluating the performance of lecturers of study programs
\end{abstract}

Keywords: decision support system, evaluation, lecturer, TOPSIS, tridharma

\section{PENDAHULUAN}

Dalam perkembangan dunia pendidikan yang kompetitif dan mengglobal, lembaga pendidikan membutuhkan tenaga pendidik, terutama tenaga dosen yang berprestasi tinggi. Dalam sistem perguruan tinggi dosen termasuk salah satu komponen esensial yang memiliki peran, tugas, dan tanggung jawab penting dalam mewujudkan tujuan pendidikan nasional, yaitu mencerdaskan kehidupan bangsa dan meningkatkan kualitas sumber daya manusia.

STIKOM Uyelindo Kupang berdiri pada tahun 2000 terletak di Jln. Perintis Kemerdekaan 1, Kelurahan Kayu Putih, Kecamatan Oebobo, Kota Kupang, NTT. Merupakan perguruan tinggi berbasis teknologi informasi yang memiliki tiga program studi yaitu teknik informatika strata satu, teknik informatika diploma tiga dan sistem informasi strata satu. Ketiga program studi selalu berupaya meningkatkan status akreditasi dengan peningkatan kualitas internal secara berkelanjutan dan menjadikan akreditasi sebagai strategi untuk bersaing dengan perguruan tinggi lain. Untuk menjaga kualitas, ketiga program studi secara rutin melakukan monitoring dan evaluasi kinerja dosen. Permasalahan yang sering dihadapi dalam rutinitas monitoring dan evaluasi kinerja dosen yaitu proses evaluasi kinerja yang masih bersifat objektif sehingga untuk mengatasi permasalahan yang dihadapi maka diperlukan sebuah sistem pendukung keputusan yang dapat membantu dalam mengevaluasi kinerja dosen program studi di STIKOM Uyelindo Kupang.

Sistem Pendukung Keputusan (SPK) merupakan sebuah sistem yang mampu memberikan pemecahan masalah dalam proses pemilihan alternatif tindakan untuk mencapai tujuan atau sasaran tertentu. Salah satu metode yang ada di dalam SPK yaitu metode Technique for Order Performance by Similarity to Ideal Solution (TOPSIS) yang dapat digunakan untuk mendukung pengambilan keputusan multikriteria. Metode TOPSIS pertama kali diperkenalkan oleh Yoon dan Hwang (1981). TOPSIS menggunakan prinsip bahwa alternatif yang terpilih harus mempunyai jarak terdekat dari solusi ideal positif dan jarak terpanjang (terjauh) dari 
solusi ideal negatif untuk menentukan kedekatan relatif dari suatu alternatif dengan solusi optimal. Solusi ideal positif adalah jumlah dari seluruh nilai terbaik yang dapat dicapai untuk setiap atribut, sedangkan solusi ideal negatif terdiri dari seluruh nilai terburuk yang dicapai untuk setiap atribut. SPK dengan menggunakan metode TOPSIS pernah diterapkan pada penelitian yang berjudul sistem pendukung keputusan penentuan penerimaan mahasiswa baru jalur bidikmisi menggunakan metode TOPSIS, penelitian tersebut menghasilkan sebuah sistem yang membantu tim seleksi bidikmisi dalam proses penentuan mahasiswa baru yang layak diterima masuk jalur bidikmisi (Puspitasari, et al. 2017).

Tujuan penelitian ini yaitu membuat sebuah sistem pendukung keputusan untuk penilaian kinerja dosen program di STIKOM Uyelindo Kupang menggunakan metode TOPSIS.

\section{TINJAUAN PUSTAKA}

Penelitian dilakukan menggunakan metodologi yang terdiri dari langkah-langkah sebagai berikut:

\section{a. Observasi}

Dengan melakukan pengamatan secara langsung terhadap objek yang diteliti untuk mendapatkan informasi secara aktual. Observasi merupakan salah satu teknik pengumpulan data yang cepat dan cukup efektif terhadap suatu objek dalam penelitian.

\section{b. Studi Pustaka}

Informasi yang relevan dengan topik atau masalah yang menjadi obyek penelitian. Informasi tersebut dapat diperoleh dari bukubuku, karya ilmiah atau jurnal. Dengan melakukan studi kepustakaan,peneliti dapat memanfaatkan semua informasi dan pemikiran-pemikiran yang relevan dengan penelitiannya.

\section{c. Wawancara}

Metode ini dilakukan dengan mewawancarai dosen program studi dan LP3M di STIKOM Uyelindo Kupang. Wawancara dilakukan dengan kegiatan tanya jawab secara face to face dengan orang yang berhubungan langsung dalam penelitian yang dilakukan untuk memperoleh data yang dapat menjelaskan atau menjawab suatu permasalahan yang sedang diteliti.

Bahan penelitian yang digunakan dalam penelitian berupa data dari program studi dan LP3M, yang meliputi kegiatan dosen dibidang pengajaran, penelitian dan pengabdian pada masyarakat, serta buku maupun jurnal yang berkaitan dengan SPK, termasuk dengan SPK menggunakan metode TOPSIS dan juga dengan mengakses referensi dari internet sesuai dengan topik penelitian dan dapat dipertanggung jawab secara ilmiah.

Prosedur analisis data yang digunakan untuk penelitian tentang mengevaluasi kinerja dosen program studi digambarkan ke dalam flowchart sebagai berikut:

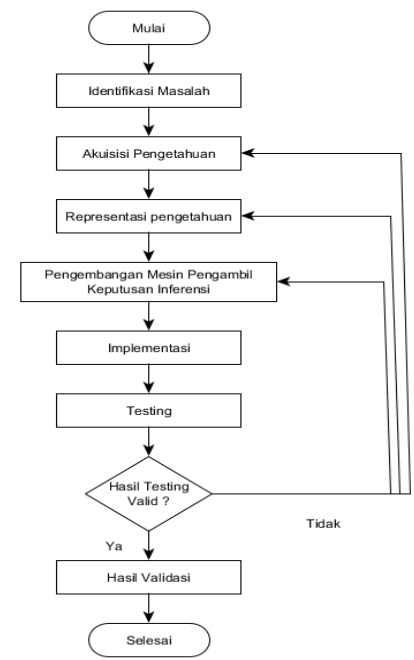

Gambar 1. Prosedur Analisis Data

a. Identifikasi masalah

Pengenalan masalah penelitian secara umum diperoleh melalui studi literatur serta pengamatan langsung di lokasi penelitian yaitu STIKOM Uyelindo Kupang.

b. Akuisisi pengetahuan

Proses pengumpulan pengetahuan, pemindahan dan perubahan masalah keahlian dari pakar atau dari sumber dokumen pengetahuan yang dimasukan kedalam komputer untuk pengembangan dari basis pengetahuan.

c. Representasi

Metode yang digunakan untuk pengkodean pengetahuan (knowledge base). Dari masalah yang ditemukan maka representasi pengetahuannya sebagai berikut:

Tabel 1. Daftar Dosen

\begin{tabular}{cl}
\hline No. & \multicolumn{1}{c}{ Nama Dosen } \\
\hline 1 & Petrus Katemba, M.T \\
2 & Fransiskus M.H. Tjiptabudi, M.M \\
3 & Edwin A. Umbu Malahina, M.T \\
4 & Franki Y. Bisilisin, M.Kom \\
5 & Gregorius R. Iriane, M.T \\
6 & Benediktus Y. Bhae, M.T
\end{tabular}




\begin{tabular}{cl}
\hline No. & \multicolumn{1}{c}{ Nama Dosen } \\
\hline 7 & Semlinda J. Bulan, M.Kom \\
8 & Yohanes Payong, M.T \\
9 & Mardhalia Saitakela, M.T \\
10 & Dewi Anggraini, M.T \\
11 & Remerta N. Na'atonis, M.Cs \\
12 & Skolastika S. Igon, M.T \\
13 & Menhya Snae, M.Kom \\
14 & Rosmidar, M.M \\
15 & Jimi Asmara, M.Kom \\
16 & Bruno Sukarto, M.M \\
17 & Marinus I.J. Lamabelawa, M.Cs \\
18 & Tri Ana Setyarini, M.Cs \\
19 & Yohanes Malelak, M.Cs \\
20 & Max Abr. Soleman Lenggu, M.T \\
21 & Yohanes Suban Belutowe, M.Kom \\
22 & Benyamin J. Belalawe, M.Kom \\
23 & Emanuel Safirman Bata, M.T \\
24 & Yampi R. Kaesmetan, M.Kom \\
25 & Meliana O. Meo, M.Kom \\
26 & Marlinda V. Overbeek, M.Kom \\
27 & Sumarlin, M.Kom \\
28 & Erna Rosani Nubatonis, M.T \\
29 & Heni, M.Hum \\
30 & Dr. Hasibun Asikin \\
31 & Benjamin, M.A \\
32 & Yosep Jacob Latuan, M.H \\
\hline &
\end{tabular}

Tabel 2. Kriteria bidang pengajaran

\begin{tabular}{llc}
\hline No. & \multicolumn{1}{c}{ Kriteria } & Bobot \\
\hline 1. & $\begin{array}{l}\text { Memenuhi jumlah tatap } \\
\text { muka sesuai dengan jadwal } \\
\text { yang di jadwalkan }\end{array}$ & 4 \\
& $\begin{array}{l}\text { Penyerahan instrumen } \\
\text { mengajar } \\
\text { silabus, kontrak, bahan ajar, } \\
\text { presentasi) }\end{array}$ & 4 \\
3. & $\begin{array}{l}\text { Penyerahan soal ujian } \\
\text { 4. Penyerahan nilai akhir }\end{array}$ & 4 \\
\end{tabular}

Tabel 3. Kriteria bidang penelitian

\begin{tabular}{clc}
\hline No. & \multicolumn{1}{c}{ Kriteria } & Bobot \\
\hline \multirow{2}{*}{1} & Tema atau topik selaras dengan visi / \\
& misi Prodi & \\
& Sangat sesuai & 3 \\
& Cukup Sesuai & 2 \\
& Tidak Sesuai & 1
\end{tabular}

\begin{tabular}{clc}
\hline No. & \multicolumn{1}{c}{ Kriteria } & Bobot \\
\hline 2 & Level publikasi & \\
& Internasional & 3 \\
& Nasional & 2 \\
& Nasional tak & 1 \\
& terakreditasi & \\
3 & Proposal & 1 \\
& Ada & 0 \\
& Tidak ada & \\
4 & Laporan Penelitian & 1 \\
& Ada & 0 \\
& Tidak ada & 1 \\
5 & Sasaran Penelitian ke masyarakat \\
& Ada & 0 \\
& Tidak ada & 1 \\
6 & Potensi Income Lembaga & \\
& Ada & 0 \\
& Tidak ada &
\end{tabular}

Tabel 4. Kriteria bidang pengabdian masyarakat

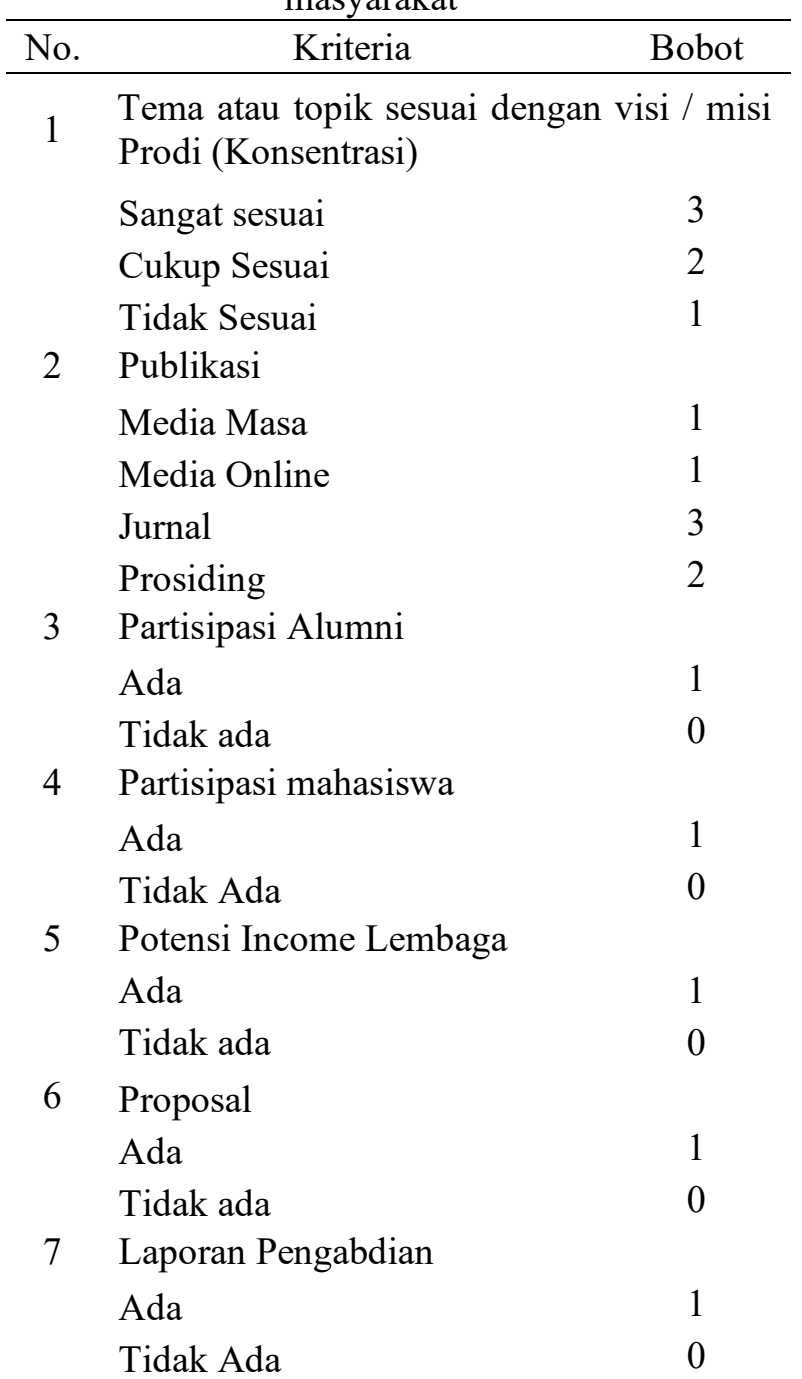




\begin{tabular}{rlc}
\hline No. & \multicolumn{1}{c}{ Kriteria } & Bobot \\
\hline 8 & Sasaran mitra kerja sama & \\
& Ada & 1 \\
& Tidak ada & 0 \\
\hline
\end{tabular}

d. Pengembangan mesin pengambil keputusan inferensi

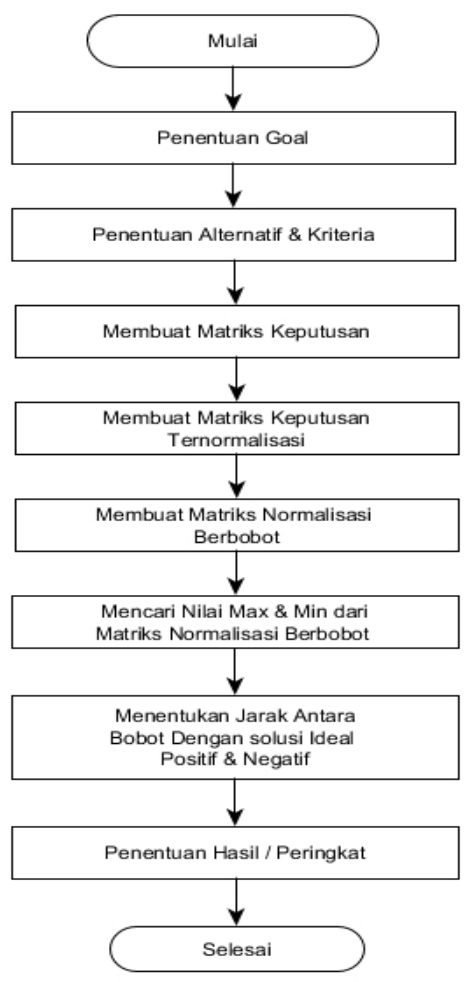

Gambar 2. Model perhitungan TOPSIS

e. Implementasi

Mekanisme pengembangan perancangan sistem yang telah dibuat menjadi sebuah aplikasi menggunakan Matlab.

\section{f. Testing}

Mengukur sejauh mana konsistensi perhitungan data terhadap pembobotan sehingga menghasilkan pilihan alternatif yang akurat. Jika hasil testing tidak valid maka sistem akan memeriksa kembali langkah akuisisi pengetahuan sampai implementasi. Jika perhitungan telah valid maka perhitungannya selesai. Pada tahap ini dilakukan dengan mengujikan hasil dengan menggunakan analisis sensitifitas. Pengujian sensitifitas dilakukan pada variabel yang berbeda jika bobot dinaikkan apakah berpengaruh pada perubahan peringkat atau tidak.

\section{HASIL DAN PEMBAHASAN}

Pembangunan aplikasi evaluasi kinerja dosen di bidang tridharma menggunakan metode TOPSIS, merupakan sebuah perangkat lunak yang dibangun untuk mempermudah proses evaluasi kinerja dosen yang akan memberikan hasil berupa urutan peringkat untuk dosen yang memiliki kinerja terbaik.

a. Antarmuka login

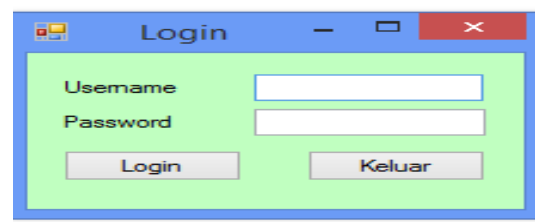

Gambar 3. Antarmuka Login

b. Antarmuka utama

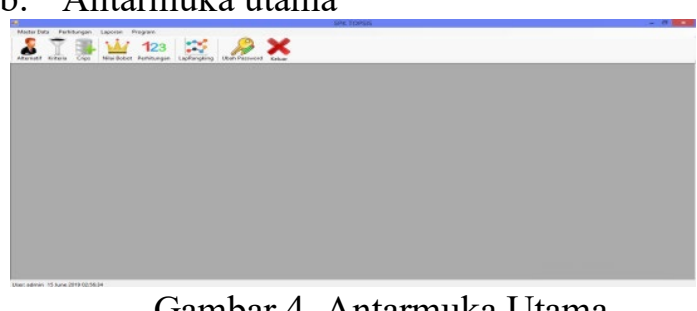

Gambar 4. Antarmuka Utama

c. Antarmuka alternatif

Dalam antarmuka master data terdapat antarmuka mengolah data alternatif. Antarmuka mengolah data alternatif bertujuan agar pengguna bisa menginput data alternatif. Tampilan antarmuka mengolah data alternatif dapat dilihan pada Gambar 5 berikut ini.

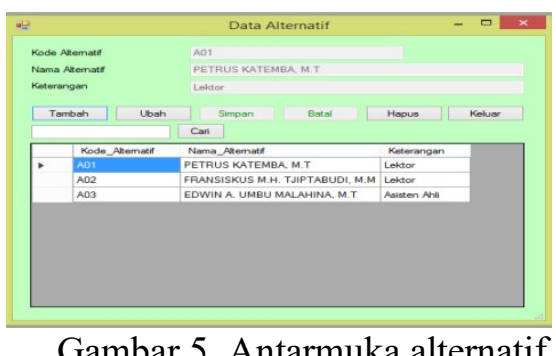

\section{d. Antarmuka kriteria}

Dalam antarmuka master data terdapat antarmuka mengolah data kriteria. Antarmuka mengolah data kriteria bertujuan agar pengguna bisa menginput data kriteria. Tampilan antarmuka mengolah data kriteria dapat dilihan pada Gambar 6 berikut ini.

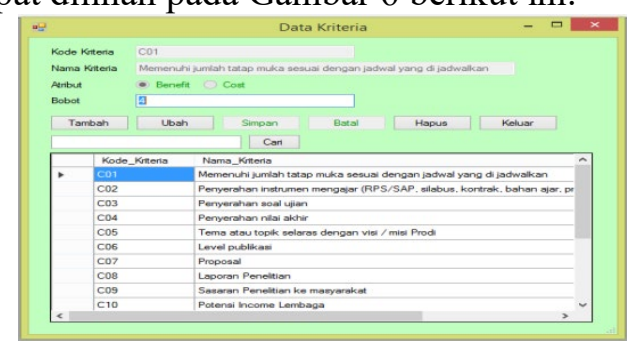

Gambar 6. Antarmuka kriteria

e. Antarmuka crips. 
Dalam antarmuka master data terdapat antarmuka mengolah crips. Antarmuka mengolah data crips bertujuan agar pengguna bisa menginput nilai kriteria ke dalam data crips. Tampilan antarmuka mengolah data crips dapat dilihan pada Gambar 7 berikut ini.

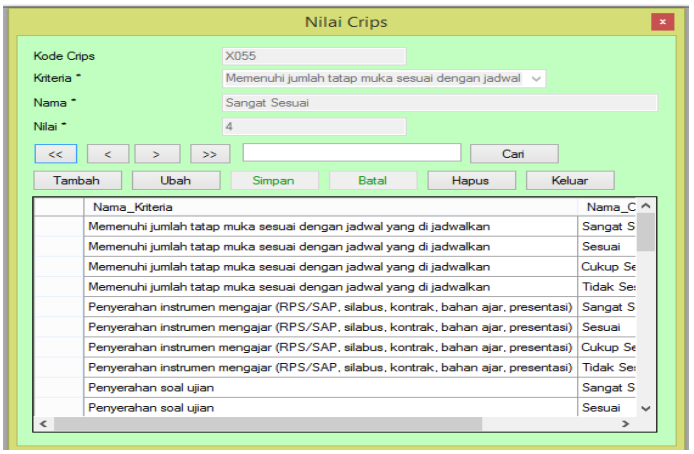

Gambar 7. Antarmuka Crips

f. Antarmuka nilai bobot.

Dalam antarmuka perhitungan terdapat antarmuka nilai bobot. Antarmuka nilai bobot bertujuan agar pengguna bisa menginput nilai bobot untuk di evaluasi. Tampilan antarmuka nilai bobot dapat dilihan pada Gambar 8 berikut ini.

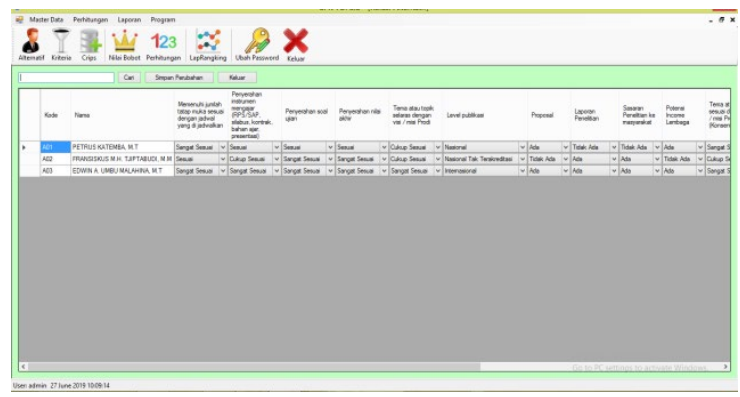

Gambar 8. Antarmuka nilai bobot

g. Antarmuka perhitungan.

Dalam antarmuka perhitungan terdapat antarmuka perhitungan. Antarmuka perhitungan bertujuan agar pengguna bisa menghitung hasil evaluasi dengan menggunakan metode TOPSIS. Tampilan antarmuka perhitungan dapat dilihan pada Gambar 9 berikut ini

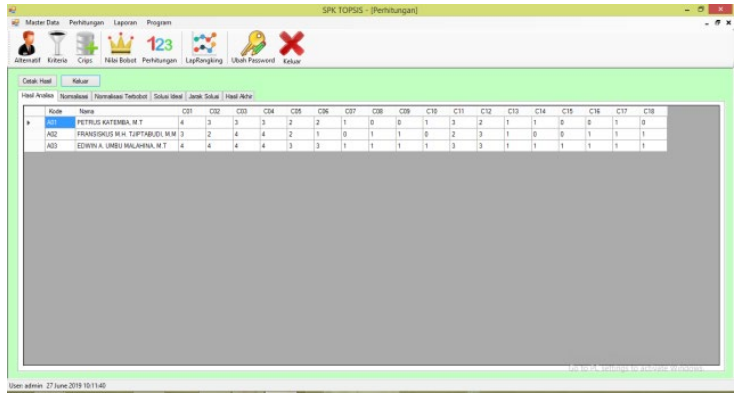

Gambar 9. Antarmuka perhitungan

h. Antarmuka cetak laporan rangking.

Antarmuka mengolah cetak laporan rangking berfungsi sebagai cetak laporan rangking hasil perhitungan yang akan digunakan admin sebagai laporan kepada pimpinan atau sesuai kebutuhan. Antarmuka cetak laporan hasil perhitungan dapat dilihat pada Gambar 10.

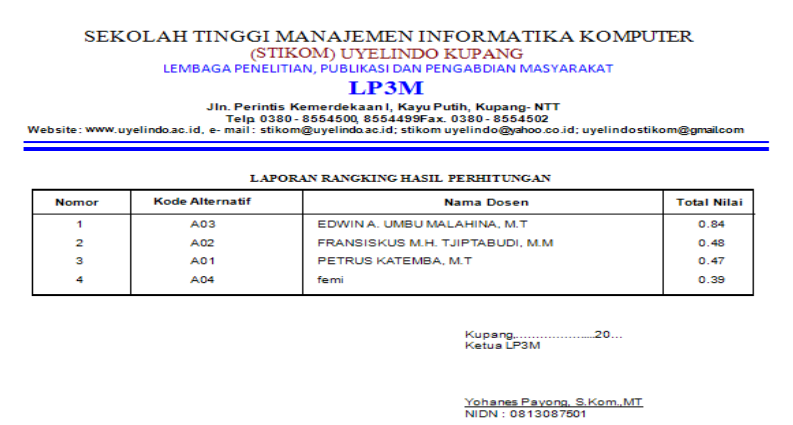

Gambar 10. Antarmuka cetak laporan rangking

\section{i. Antarmuka ubah password}

Antarmuka ubah password merupakan antarmuka yang digunakan oleh admin untuk memasukan identitas pengguna serta password yang tidak diketahui oleh oranglain atau bersifat rahasia, sehingga hanya dapat diakses oleh pengguna password saja. Antarmuka ubah password dapat dilihat pada Gambar 11.

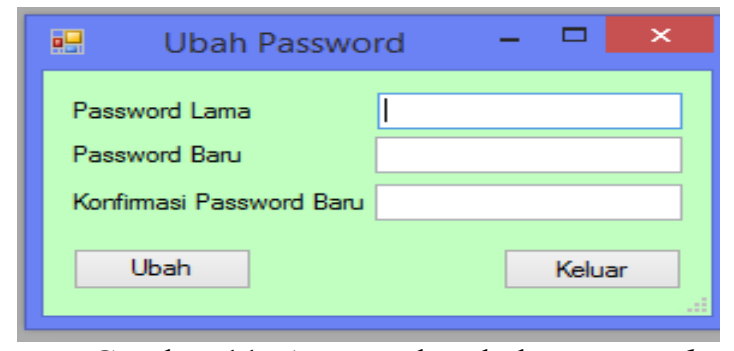

Gambar 11. Antarmuka ubah password

Pengujian sistem perangkat lunak dilakukan oleh pembuat aplikasi untuk menguji fungsi - fungsi yang terdapat dalam sistem. Saat pengujian sistem dilakukan, penulis menggunakan metode analisis sensitivitas. Pengujian dengan metode analisis sensitivitas yang menitik beratkan pada pengujian sensitivitas sistem terhadap kondisi yang berubah dengan menganalisis akurasi perhitungan sistem. Sasaran dari analisis sensitivitas adalah menguji sensitivitas sebuah sistem terhadap perubahan bobot kriteria. 


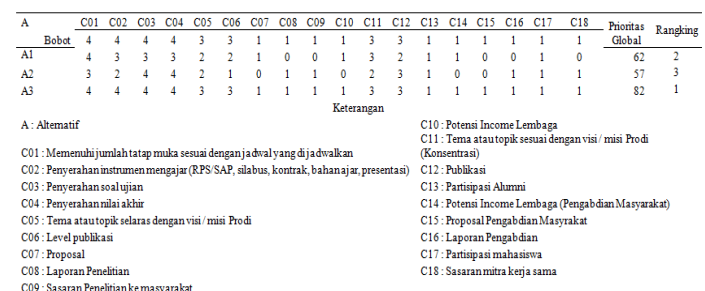

Gambar 12. Tabel Prioritas global

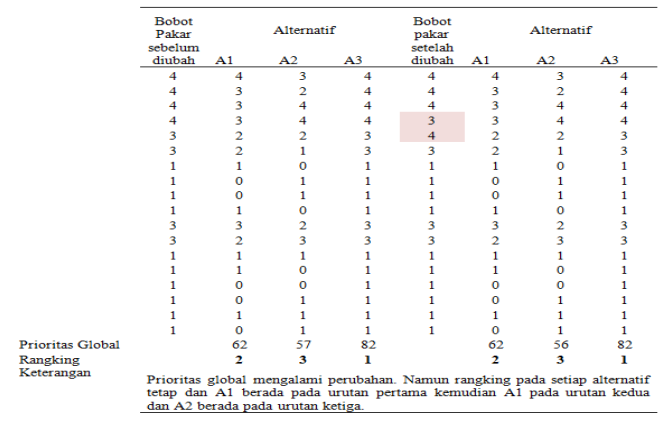

Gambar 13.Tabel Analisis sensitivitas terhadap perubahan bobot kriteria penyerahan nilai akhir dan kriteria tema atau topik selaras dengan visi / misi prodi

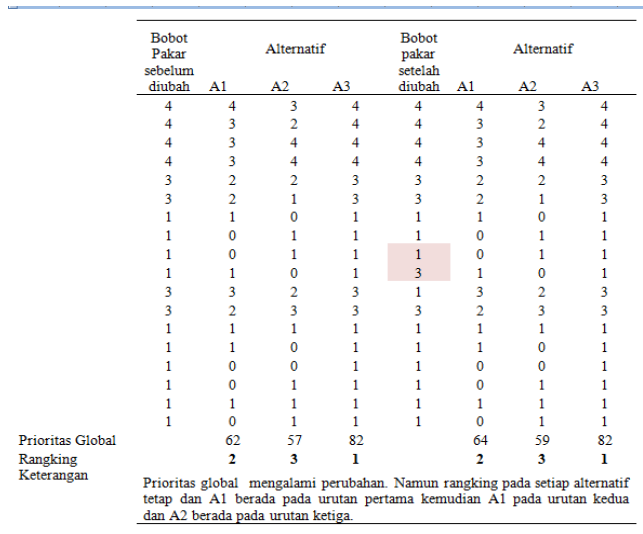

Gambar 14. Tabel Analisis sensitivitas

terhadap perubahan bobot criteria potensi income lembaga dan kriteria tema atau topik selaras dengan visi / misi prodi (konsentrasi). Dari analisis sensitivitas dapat disimpulkan bahwa perubahan bobot pada setiap kriteria dengan nilai bobot yang melebihi nilai bobot kriteria lainya akan merubah prioritas global dan rangking pada setiap alternatif.

\section{KESIMPULAN}

Berdasarkan hasil penelitian dapat disimpulkan bahwa telah diimplementasikan sebuah aplikasi evaluasi kinerja dosen di STIKOM Uyelindo Kupang menggunakan metode TOPSIS. Berdasarkan pengujian menggunakan analisis sensitivitas dapat disimpulkan bahwa perubahan bobot pada setiap kriteria dengan nilai bobot yang melebihi nilai bobot kriteria lainya akan merubah prioritas global dan rangking pada setiap alternatif.

Sebagai saran untuk penelitian selanjutnya adalah menggunakan metode yang dapat membedakan secara tegas nilai skala kriteria sehingga menjadi pembatas yang lebih tepat terhadap hasil perhitungan.

\section{DAFTAR PUSTAKA}

[1] Agustian Bobi, Oke Wibowo. 2018. Perancangan Sistem Penunjang Keputusan Pemilihan Anak Asuh Menggunakan Metode Technique For Others Reference By Similarity To Ideal Solution (Topsis) Pada Laz Sejahtera Ummat. Jurnal Informatika Universitas Pamulang Vol. 3, No. 2.

[2] Direktorat Jenderal Pendidikan Tinggi Departemen Pendidikan Nasional. 2010. Pedoman Beban Kerja Dosen Dan Evaluasi Pelaksanaan Tridharma Perguruan Tinggi. Jakarta [ID].

[3] Fakultas Ilmu Pendidikan Universitas Pendidikan Indonesia. 2009. Pedoman Penilaian Kinerja Dosen..

[4] Linda Atika. 2010. Sistem Penunjang Keputusan Penilaian Kinerja Pemilihan Dosen Berprestasi Menggunakan Metode AHP. Jurnal Imiah MATRIK Vol.12. No.3: 1-10.

[5] Puspitasari D, Mustika M, Fitrah A G. 2017. Sistem Pendukung Keputusan Penentuan Penerimaan Mahasiswa Baru Jalur Bidikmisi Menggunakan Metode Topsis (Studi Kasus : Politeknik Negeri Malang). Jurnal Informatika Polinema Volume 4, Edisi.

[6] Sari RE, Alfa S. 2014. Penilaian Kinerja Dosen Dengan Menggunakan Metode AHP. Seminar Nasional Informatika.

[7] Sidik Muuhamad. 2011. Sistem Informasi Evaluasi Kinerja Dosen Pada Fakultas Sains Dan Teknologi Universitas Islam Negeri Syarif Hidayatullah Jakarta. [Skripsi]. Jakarta [ID] : Universitas Islam Negeri Syarif Hidayatullah.

[8] Zahraini. 2014. Kinerja Dosen Dalam Meningkatkan Kemampuan Akademik (Hard Skill) Dan Penguasaan Keterampilan (Soft Skill) Pada Mahasiswa PKK FKIP UNSYIAH. Jurnal ilmiah DIDAKTIKA. Vol. XIV, No. 2, 3

[7] Ompusunggu E.A., Ratnawati D.E., dan MuflikhahLailil. 2017. Identifikasi 
Penyakit Tanaman Jarak Pagar Menggunakan Metode Fuzzy K-Nearest Neighbor (FK-NN). Jurnal Pengembangan Teknologi Informasi dan Ilmu Komputer. Vol. 1. No. 5, Mei 2017.Hlm. 368-377.

[8] Prasetyo, Eko. 2012. Data Mining Konsep dan Aplikasi menggunakan matlab. Yogyakarta: Andi.

[9] Priyanto Dwi. 2016. Strategi Pengembalian wilayah Nusa Tenggara Timur Sebagai Sumber Ternak Sapi Potong. Jurnal Litbang Pertanian. Vol. 35. No. 4 Desember 2016. Hlm. 167-178.

[10] Rialdi B.R, Hidayat N, Suprapto. 2018. Identifikasi Penyakit Pada Kambing Menggunakan Metode Fuzzy KNearestNeighbor (F-KNN). Jurnal Pengembangan Teknologi Informasi dan Ilmu Komputer. Vol. 2. No. 10, Oktober 2018. Hlm. 4312-4317

[11] Tjahajati Ida,Gunanti, Suwarno, Sutisna Abadi, Widjajanti Sri, dan Raharjo Enuh. 2014.Manual Penyakit Hewan Mamalia. Direktorat Jenderal Peternakan dan Kesehatan Hewan Kementerian Pertanian.

[12] Tyas R.D.O, Soebroto A.A, Furqon M. Tanzil. 2015. Pengembangan Sistem Pakar Diagnosa Penyakit Sapi Potong Dengan Metode Fuzzy K-Nearest Neighbour. Journal of Environmental Engineering \& Sustainable Technology. Vol. 02 No. 01, Juli 2015, Hlm. 58-66 